\title{
THE MECHANISM OF APNEA CAUSED BY INTRAVENOUSLY INJECTED NICOTINE AND AMINOCORDIN
}

\author{
NOBUYUKI NAGASAKI
}

Department of Pharmacology, Totiori University, School of Medicine, Yonago

Received for publication July 21, 1952

There have been many studies on the respiratory action of nicotine in the recent twenty years, and it has been known that intravenously injected nicotine causes an arrest of respiration. Gold and Brown (1) described it as "nicotine apnea" and divided into two types: brief, primary and prolonged, secondary. The latter, which was observable only after the application of a large dose, was explained as the peripheral curarelike action of nicotine, because phrenic discharges in action current lasted for a while after the respiration had ceased [Gold and Brown(1), Gold and Modell(2)]. The mechanism of the former, which can be shown in a small dose of nicotine, has not been so far clearly explained. The present study was undertaken to elucidate this mechanism and to find out the same type of apnea, caused by some other drugs.

\section{METHODS}

Every experiment was done on rabbits anesthetized with urethane $(0.5-1.0$ $\mathrm{g} / \mathrm{kg}$ ). The phrenic nerve, usually the left one, was isolated from the connective tissue at the cervical part and severed at the most distal point of branch from $\mathrm{C}_{3}$. The central section of the nerve was mounted on 2 nonpolarizable boot electrode about $3 \mathrm{~mm}$ apart. Considerable care was necessary to prevent the drying of the nerva by repeated applications of physiological salt solution. The action current of phrenic nerve was amplified by a resistance-capacity coupled amplifier and recorded by electromagnetic oscillograph, being observed by cathode ray oscillograph.

The respiratory movement was recorded simultaneously by Hukuhara's method(3) optically, in which the contraction of the dorsal slip of diaphragm was used as an index.

In order to compare the movement of diaphragm by Hukuhara's method with the respixatory movement by the method through tracheal cannula, usually used, kymographical recordings were also carried out.

\section{RESULTS}

Under normal conditions, phrenic discharges of rabbits under urethane anesthesia were found to begin immediately before each contraction of dia- 
phragm, possessing a frequency of about 80 to 150 per second. They increased in size during inspiration, terminated more or less abruptly just before relaxation and disappeared during expiratory phase (lig. 1a).
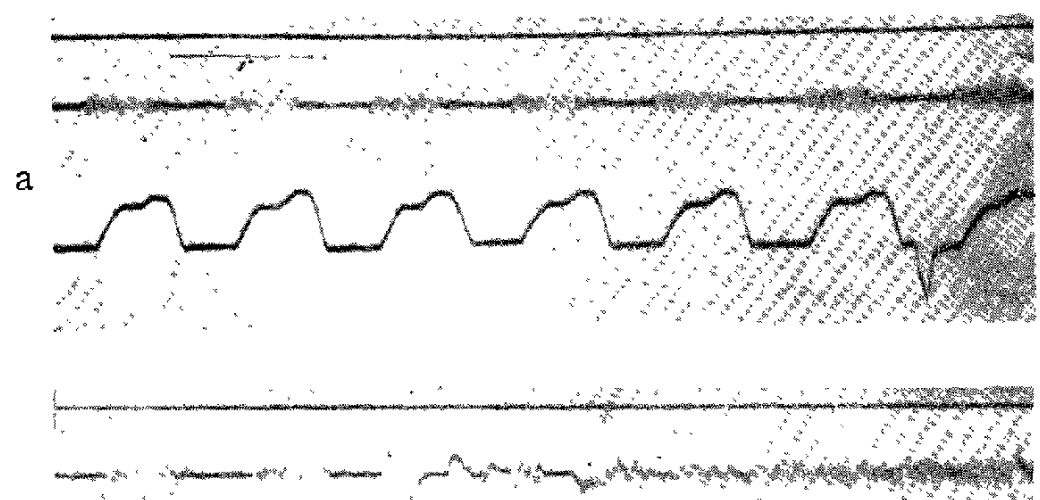

b
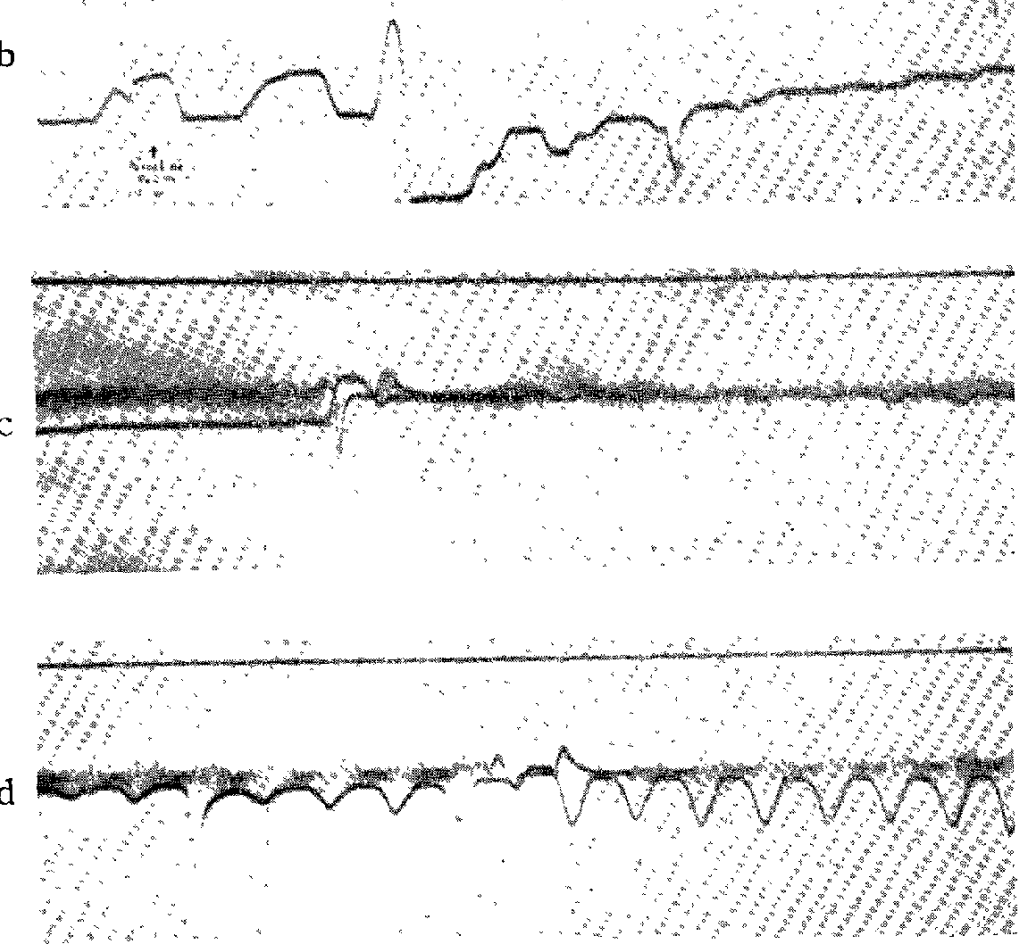

FIG. 1. The effect of nicotine on phrenic discharges and respiratory movement.

Upper record: Phrenic discharges

Lower record: Respiratory movement by Hukuhara's method

a: Before injection

$\mathrm{b}$ : Immediately after intravenous injection of nicotine, in the dose of $0.2 \mathrm{mg} / \mathrm{kg}$

c: 3 seconds after $b$

$d$ : Continued from $c$ 
A brief apnea, lasting only a few seconds, occurred instantaneously after the intravenous injection of nicotine in doses of $0.1-0.3 \mathrm{mg} / \mathrm{kg}$, and was followed in turn by a marked acceleration of respiration. In this stage of apnea, continuous impulses were observed in phrenic action current, while the diaphragm fell into a contractive tonic condition (inspiratory arrest) (Fig. 1b, c). The impulses of phrenic nerve, however, were not completely uniform, and a slight tendency of periodicity could be recognized, which gradually becane obvious until the respiration reappeared (Fig. Ic, d).

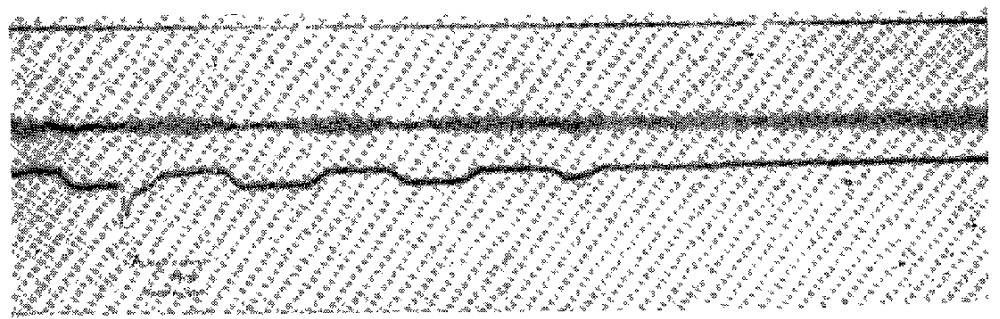

FIG. 2. The effect of aminocordin $(50 \mathrm{mg} / \mathrm{kg})$ on phrenic discharges aad respinatory movement (Remarks are the same as that of Fig. 1).

Aminocordin (Coramin), injected intravenously in a dose of $50 \mathrm{mg} / \mathrm{kg}$, caused similar results (Fig. 2), although complete apnea was hardly observed in the urethanized rabbit, while in the unanesthetized animal the recording was disturbed by the convulsion invited by the drug.

a
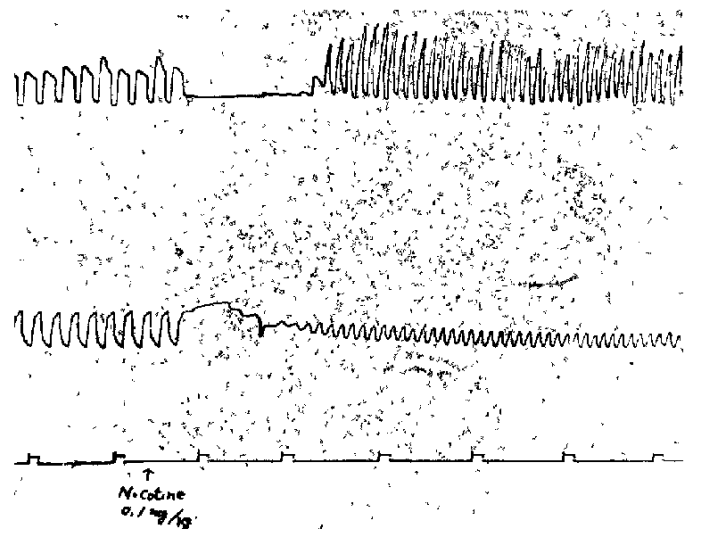
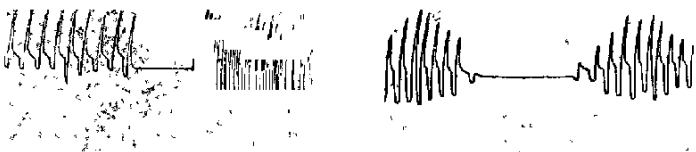

b

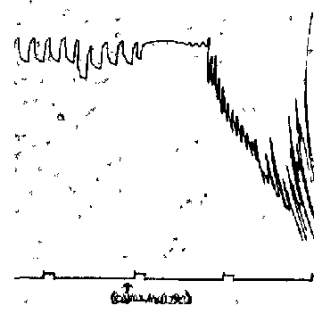

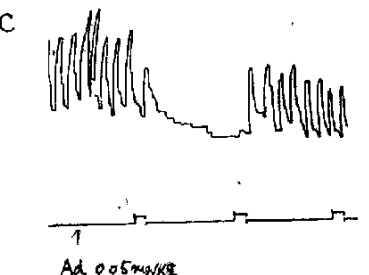

Ad eorkask

FIG. 3. The effect of nicotme, aminocordin and adrenaline on respiratory movement recorded kymographicaliy.

Upper tracing: The record through tracheal cannula

Lower tracing; The record by Hukuhara's method (upwards; contraction, downwards: relaxation of diaphragm)

Time interval: 10 seconds

a: Nicotine $0.1 \mathrm{mg} / \mathrm{kg}$ int ravetousiy

b: Aminocordin $50 \mathrm{mg} / \mathrm{kg}$

c: Adrenalize $0.05 \mathrm{mg} / \mathrm{kg}$ 
The kymographical recordings of respiratory movement by Hukuhara's method revealed a tonic contractive arrest of diaphragm in the stage of apnea, caused by intravenously injected nicotine or aminocordin (Fig. 3a, b). In adrenaline apnea, on the contrary, the diaphragm fell into a relaxed condition (Fig. 3c).

\section{DISCUSSION}

In the pharmacological study on respiration, the recording of phrenic action current is essential to determine the mechanism of drug action, whether it is of central or peripheral nature. Though the phrenic discharges had been recorded since 1921 by Gasser and Newcomer(4), the first investigators, who utilized them in pharmacological study, were Gold and Modell(2). They studied the respiratory effects of several drugs including nicotine by means of phrenic potentials, and contributed to the mechanism of respiratory failure following a fatal dose of nicotine in cats and dogs, but let the mechanism of primary nicotine apnea remain obscure. No other reporter, who observed phrenic action current, has touched on the nicotine apnea.

In the present investigation, it is obvious that the respiratory center is not depressed but extremely stimulated by nicotine in small doses, because the phrenic discharges increase in the stage of apnea. The diaphragm, receiving continuo:us impulses from the center, falls into a tonic contractive state, as a result of Hukuhara's method evidently demonstrated. The mechanism of the primary nicotine apnea, therefore, must be attributed to the tetanic contraction of the diaphragm (and probably of all respiratory muscles) owing to the excessive stimulation of the center. We can call this type of apnea as "hy perpnoeic apnea", contrary to the usually observed apnea in the case of respiratory failure. The "hyperpnoeic apnea" is characterized by the following frequent and strong respiration. A quite analogous mechanism is conceivable in the apnea by aminocordin, which appears immediately after intravenous injection and succeeds to respiratory excitement. Apnea after electroshock, as. Kan(5) in our laboratory has previously anticipated, can also be ascribed to the same mechanism.

Nicholson and Sobin(6) have reported previously that nicotine applied to the floor of the fourth ventricle of dogs caused an instantaneous apnea as a result of stimulation of an expiratory mechanism. Kaida(7) has recently described that nicotine and analeptics (aminocordin, vitacampher etc.) caused a temporary respiratory inhibition due to the stimulation of inhibitory center of respiration after the injection into cisterna magna of rabbits. According to our interpretation above-mentioned, however, it may be unnecessary to hypothesize the stimulation of the inhibitory center or expiratory mechanism. 
In cats and dogs, inspiratory or expiratory apnea after nicotine injection has been reported by Semba and Irisawa(8), but in the present experiments in rabbits the expiratory apnea was not observed.

Mizoguchi(9) observed that aminocordin increased the tone of diaphragm in urethanized rabbits, but could not recognize a respiratory arrest, probably due to deep anesthesia.

In adrenaline apnea a decrease of phrenic discharges has been already proved by Komaki(10) and Mizoguchi(9). The relaxation of diaphragm by Hukuhara's method in this investigation agrees with it.

It is difficult, as a rule, to differentiate between the two types of apnea (hyperpnoeic or hypopnoeic) by the recording method of respiratory movements customarily used. For this purpose, the observation of the tone of diaphragm by Hukuhara's method will be suitable, although the recording of phrenic action current is the best.

\section{SUMMARY}

The action current of phrenic nerve was recorded oscillographically in rabbits and the following results were obtained.

1. The respiratory arrest immediately after the intravenous injection of nicotine is "hyperpnoeic apnea", which is due to the extreme stimulation of respiratory center.

2. The apnea caused by intravenously injected aminocordin is also attributable to the same mechanism. On the contrary, adrenaline apnea may be ascribed to the inhibition of respiratory center.

\section{REFERENCES}

1) GoLd, H. AND BRown, F.: J. Pharmacol. \& Exper. Therap. 51, 463 (1935)

2) GOLD, H. AND MODELl, W.: lbid. 57, 310 (1936)

3) Hukuhara, T.: J. Physiol. Society Japan 12, 206 (1950)

4) GASSER, H. S. AND NEWCOMER, H. S.: Am. J. Physiol. 57, I (1921)

5) KAN, N.: Folia pharmacol. japon. 48, 42 (1952)

6) Nicholson, H. C. ANd Sobin, S.: Am. J. Physiol. 123, 766 (1938)

7) KAIDA, W.: Igaku Kenkyu (Acta Medica) 21, 572 (1951)

8) Semba, T. ANd IRISAWA, H.: I. Physiol. Socieiy Japan 13, 233 (1951)

9) MIzogUchI, M.: Igaku Kenkyu 21, 1113 (1951)

10) KoмAKI, M.: Folia pharmacol. japon. 43, 27 (1947) 